\title{
The relevance of serum levels of long chain omega-3 polyunsaturated fatty acids and prostate cancer risk: A meta-analysis
}

\author{
Michael E. Chua, MD;* Maria Christina D. Sio, MD;† Mishell C. Sorongon, MD, Marcelino L. Morales Jr., MD \\ $D P B U F P U A^{*}$
}

*Institute of Urology and Research and Biotechnology Division, St. Luke's Medical Center, Philippines; †Department of ENT, St. Luke's Medical Center, Philippines; 施epartment of Preventive and Community Medicine, St. Luke's College of Medicine, Philippines; \#Institute of Urology, St. Luke's Medical Center, and National Kidney and Transplant Institute, Philippines

Cite as: Can Urol Assoc J 2013;7(5-6):e333-43. http://dx.doi.org/10.5489/cuaj.1056 Published online May 13, 2013.

\section{Abstract}

Objective: Our objective was to systematically analyze the evidence for an association between serum level long chain omega-3 polyunsaturated fatty acid (n-3 PUFA) and prostate cancer risk from human epidemiological studies.

Study Procedures: We searched biomedical literature databases up to November 2011 and included epidemiological studies with description of long chain n-3 PUFA and incidence of prostate cancer in humans. Critical appraisal was done by two independent reviewers. Data were pooled using the general variance-based method with random-effects model; effect estimates were expressed as risk ratio with $95 \%$ confidence interval $(\mathrm{Cl})$. Heterogeneity was assessed by $\mathrm{Chi}^{2}$ and quantified by $\mathrm{I}^{2}$, publication bias was also determined.

Results: In total, 12 studies were included. Significant negative association was noted between high serum level of n-3 PUFA docosapentaenoic acid (DPA) and total prostate cancer risk (RR:0.756; 95\% Cl 0.599, 0.955; $p=0.019$ ). Likewise, a positive association between high blood level of fish oil contents, eicosapentaenoic acid (EPA) and docosahexaenoic acid (DHA), and high-grade prostate tumour incidence (RR:1.381; 95\% Cl 1.050, 1.817; $p=0.021$ ) was noted; however, this finding was evident only after adjustment was done on interstudy variability through the removal of a lower quality study from the pool.

Conclusions: High serum levels of long chain n-3 PUFA DPA is associated with reduced total prostate cancer risk. While high blood level of EPA and DHA is possibly associated with increased high-grade prostate tumour risk.

\section{Introduction}

Due to widespread use of prostate-specific antigen (PSA) screening, more prostate cancer is being detected. To find ways to prevent prostate cancer, several studies have tried to identify risk factors (i.e., lifestyle and diet). Researchers have studied the effects of long-chain omega-3 polyunsaturated fatty acids (n-3 PUFA), found in marine animals, on the prevalence of prostate cancer. These mechanisms of n-3 PUFA regulate inflammation via the eicosanoid pathway ${ }^{1-4}$ and modify androgen production. ${ }^{5}$ In particular, dietary intake of long-chain n-3 PUFA or its individual components (eicosapentaenoic acid [EPA], docosahexaenoic acid [DHA], docosapentaenoic acid [DPA]), have been proposed to have an association with prostate cancer risk; however, these results have been inconsistent, largely variable and heterogeneous. ${ }^{6-9}$ These inconsistent results were mainly due to research variations in dietary assessment techniques and under- or overreporting of values, which decreased the accuracy of measuring individual's fatty acid intake. ${ }^{10,11}$ Experts have suggested that levels of fatty acids in blood, tissue or erythrocyte membranes could provide a more reliable method of estimating fatty acid consumption. ${ }^{12-16}$ We conducted a meta-analysis to quantitatively estimate the correlation between blood levels of long chain n-3 PUFA and its derivatives with the incidence of prostate cancer in epidemiological studies.

\section{Methods}

We searched biomedical electronic databases, regardless of language. MEDLINE, UNBOUND MEDLINE, EMBASE, Science Direct, OVID, Proquest (database of dissertation and thesis) and the Cochrane Library were searched up to November 2011. MEDLINE Medical Subject Heading $(\mathrm{MeSH})$ terms used were "omega 3 fatty acids" AND "prostate neoplasm." Common keyword searches were "prostate cancer," "carcinoma," "neoplasm," "tumor," "omega," "long chain fatty acids" and "polyunsaturated." References from studies that met our inclusion criteria and review articles or textbooks were searched for potentially relevant titles. External peer reviewers were asked to identify additional relevant studies. Industry/nutrition experts were also inquired to obtain unpublished data.

We included prospective or retrospective case control studies of human population, where the blood level of long 
chain n-3 PUFA (DHA, DPA and EPA) was determined as exposure and incidence of prostate cancer was analyzed as outcome. All included studies provided effect estimates with corresponding confidence intervals pertaining to comparison between high long chain n-3 PUFA blood level and the reference group (lowest blood level). This unvarying method of comparison among the studies eliminated the differences of blood level n-3 PUFA source and ranges described in each study. Studies dealing with tissue n-3 PUFA levels were not included, since the sampling procedure was complex and usually done on high-risk patients, which could affect the reliability of effect estimates. Animal and in-vitro studies were excluded because correlation with in-vivo human physiologic outcome is uncertain. Cross-sectional and ecologic analyses were excluded, since these studies were unable to provide informative effect estimates. ${ }^{17}$

Two physician reviewers independently evaluated all citations and abstracts, and then they requested all the relevant fulltext articles (Fig. 1). All articles obtained were independently reviewed by two reviewers knowledgeable in principles of critical appraisal. When discrepancy of evaluation arose, both reviewers resolved disagreements; a senior physician resolved unsettled issues. Articles retrieved were critically appraised and scored according to the National Health Service (NHSUK) recommendation for review of qualitative studies. ${ }^{18}$ The maximum score was 11 points; studies that scored below 8 were excluded. Then, we used the Newcastle-Ottawa Quality Assessment Scale (NOQAS) of Cochrane Collaboration ${ }^{19}$ to rate each included study and enhance quality assessment, and to rank studies when heterogeneity was noted.

The general variance-based method was used to analyze the cohort studies, because variance estimates were based on adjusted measures of effect with $95 \%$ confidence interval $(\mathrm{Cl})$ that account for confounding variables and known to be superior in pooling observational data. ${ }^{19}$ Relative risk (RR) or odds ratio (OR) and corresponding $\mathrm{Cl}$, with adjustments for confounding variables, were used to estimate the risk ratio of prostate cancer incidence and subcategories (advanced and high grade type prostate tumour) with highest blood level of long chain omega-3 fatty acids component (DPA, DHA, EPA) versus the reference group. Only the most recent and comprehensive data were included when a study was published at several times and on different dates.

We used Cochran's chi-square test $(Q)$ and I squared $\left(I^{2}\right)$ to assess inter-study heterogeneity and variance, respectively. ${ }^{20}$ In cases of heterogeneity $(p<0.1)$, the source was identified by performing subgroup analyses on the basis of important differences in study design (retrospective case control vs. nested case-control). Afterwards, sensitivity analysis was repeated by excluding the study with the lowest NOQAS from the pool to acquire homogeneous pool estimates.

The random effect model was used to determine pooled effect estimates, since this model is more conservative. ${ }^{21}$ For analyzing the summation effect of long chain n-3 PUFA (DPA+DHA+EPA) and commercially available fish oil n-3 PUFA content (DHA+EPA) with prostate cancer incidence

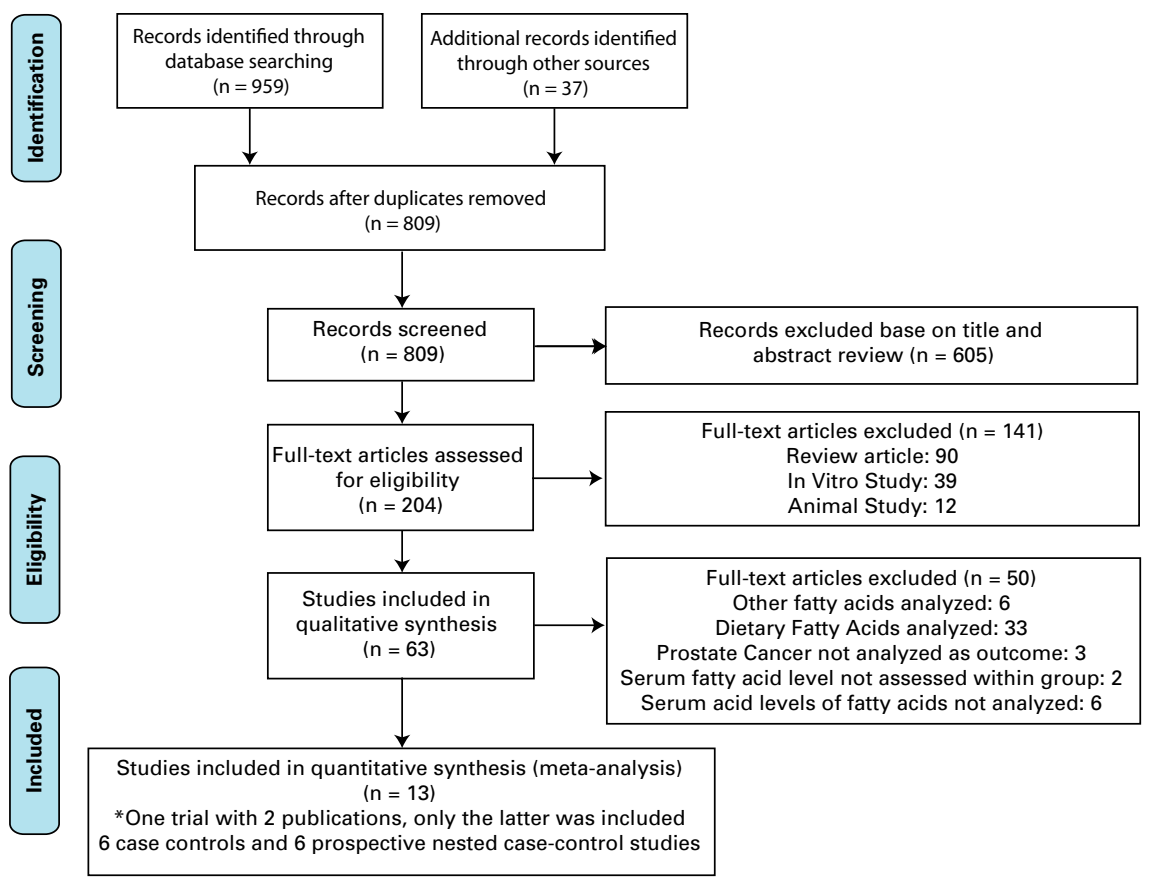

Fig. 1. Prisma chart literature search process and result. 
and its subcategories, we used a mixed effect analysis- random effects model to combine studies within each subgroup of long chain n-3 PUFA. The Comprehensive Meta Analysis software version 2 (Biostat, Englewood, $\mathrm{NJ})^{22}$ and RevMan5 ${ }^{23}$ were used for the statistical analysis of pooled data and construction of forest plots. Publication bias was examined using Egger's regression intercept, ${ }^{24}$ Begg-Mazumdar rank correlation $^{25}$ analysis and visual inspection of funnel plots. ${ }^{26}$

\section{Results}

In total, we included 12 articles for this meta-analysis: 6 case-control studies ${ }^{27-32}$ and 6 nested case control studies (Table 1). ${ }^{33-38}$ All studies uniformly compared prostate cancer risk with the groups of involved population with the highest blood level of long chain n-3 PUFA and the reference group (lowest blood level). Most studies analyzed risk of prostate cancer development as part of their studies' outcome. ${ }^{27-37}$ Four studies included advanced stage (defined as extension of tumour through the capsule) prostate cancer. ${ }^{28,35-37}$ Five studies included high-grade tumour (defined as tumour Gleason score 27 ) in their analysis of outcome..$^{30,35-38}$ The age range of the study population was 40 to 86 years old. Overall, we analyzed 4516 prostate cancer cases and 5728 matching controls.

\section{Blood level omega-3 PUFA and prostate cancer risk}

Visual inspection of funnel plot showed publication bias less likely (Fig. 2). Results showed that the pooled estimates of long chain n-3 PUFA DPA have a significant association with total prostate cancer incidence (pooled RR: $0.756 ; \mathrm{Cl}$ $0.599,0.955 ; p=0.019$ ) (Fig. 3). In the homogeneous studies $(p=0.566)$, there were no study variations $\left(I^{2}=0 \%\right)$, and no publication bias in the Begg $(p=1.0)$ and Egger's regression intercept ( $p=0.54$ ) (Table 2.1). When subgroup analysis was done by method of study (retrospective vs. prospective), the significant finding was retained in the prospective studies (pooled RR: $0.773 ; \mathrm{Cl} 0.605,0.988 ; p=0.040$ ). High blood levels of total n-3 PUFA or other derivatives (together and individually) had no significant association to total prostate cancer risk, advanced prostate cancer and high-grade prostate tumour (Table 3 ).

Significant heterogeneity was noted on the analysis of blood level n-3 PUFA DHA and EPA with total prostate cancer risk and high-grade prostate tumours (Table 2.2, Table 4 ); therefore the validity of the result was questioned. The inter-study variation ranged from $32 \%$ to $53 \%$. Source of heterogeneity was identified (Table 2.2) and a nested casecontrol study ${ }^{34}$ was removed from the pooled estimate which resulted to reduced heterogeneity and variation $\left(R^{2}\right)$.

Reviewing the summation effect of fish oil content long chain n-3 PUFA (DHA+EPA) on prostate cancer develop- ment, we found a significant positive association (pooled RR: $1.39 ; \mathrm{Cl} 1.07,1.80 ; p=0.021$ ) (Fig. 4) with high-grade prostate cancer. Adjusted inter-study heterogeneity was not significant ( $p=0.291$ ) with a small degree of inter-study variation $\left(I^{2}=17.6 \%\right)$. Publication bias of the respective n-3 PUFA subgroup analysis was not evident using Begg $(p=0.734)$, Egger's $(p=0.265,0.952)$ test (Table 4$)$ and upon visual inspection of the funnel plot (data not shown).

\section{Discussion}

Randomized clinical trials have not been done to clarify the role of n-3 PUFA in prostate cancer development due to ethical considerations and methodological limitations; as such, we investigated this relationship using the best credible epidemiological data available - case controls. Another important aspect in this meta-analysis is that all included studies were executed in the 1990s when PSA screening was utilized for early detection of prostate cancer.

After an extensive review, we found a significant negative association between high blood n-3 PUFA DPA level and total risk of prostate cancer. DPA is found in whale meat, seal oil and, to a lesser extent, in marine fatty fish oil together with other long chain n-3 PUFA series (DHA and EPA). ${ }^{39}$ Currently, few studies have been conducted to examine the biophysiological effect of DPA because of production costs. Human studies are lacking; most studies are in-vitro or with animal subjects. ${ }^{40}$ In the study by Wang and colleagues, the finding of high serum level DPA is a result of in-vivo biochemical conversion rather than mere high dietary exposure, since the commercially available supplement of long chain n-3 PUFA DPA is not common or readily available. ${ }^{40}$ Moreover, in the subgroup analysis of the pooled prospective studies, the significant association was retained; this illustrates the association as an effect of long-term lipid metabolism rather than short-term dietary exposure. Studies have shown that humans are able to biosynthesize DPA mainly through bioconversion from EPA by enzymes fatty acid elongase- 2 and 5, and could be retro-converted to EPA in the liver and kidney. ${ }^{41-43}$ The mechanism of the protective effect of DPA on prostate cancer may be explained by biochemical processes involving: reduced prostacyclin production, expression of inflammatory genes and TNF-induced necrotic cell death; competition with cycloxygenase 2 (COX2) enzymes resulting to anti-neoplastic activity via proapoptotic pathway; and inhibition of angiogenesis. ${ }^{4-49}$ Detection of such association may suggest that serum level DPA implicates individual genetic difference in biochemical characteristics of enzymatic activities, which may be further investigated as a probable new serum biomarker for prostate cancer risk assessment in the future.

Heterogeneity was noted in the analysis of association of blood level DHA and EPA with prostate cancer and high- 
Chua et al.

\begin{tabular}{|c|c|c|c|c|c|c|c|c|}
\hline Studv or Subgroup & log[Risk Ratio] & SE & Weight & $\begin{aligned} & \text { Risk Ratio } \\
& \text { IV. Random. } 95 \% \mathrm{Cl}\end{aligned}$ & & $\begin{array}{r}\text { Risk } \\
\text { IV. Rando } \\
\end{array}$ & $\begin{array}{l}\text { Ratio } \\
\text { om. } 95 \% \mathrm{Cl}\end{array}$ & \\
\hline \multicolumn{9}{|c|}{ 1.1.1 Doco sahexaenoic acid (DHA) } \\
\hline Crowe 2008 & 0.3293 & 0.1589 & $9.0 \%$ & $1.39[1.02,1.90]$ & & & & \\
\hline Godley 1996 & -1.0217 & 0.6485 & $1.0 \%$ & $0.36[0.10,1.28]$ & & & & \\
\hline Harvei 1997 & 0 & 0.3268 & $3.5 \%$ & $1.00[0.53,1.90]$ & & & & \\
\hline Mannisto 2003 & -0.3425 & 0.2928 & $4.1 \%$ & $0.71[0.40,1.26]$ & & & 一 & \\
\hline Newcomer 2001 & 0 & 0.4463 & $2.0 \%$ & $1.00[0.42,2.40]$ & & & & \\
\hline Norrish 1999 & -0.478 & 0.2352 & $5.7 \%$ & $0.62[0.39,0.98]$ & & & & \\
\hline Park 2009 & 0.1044 & 0.2138 & $6.4 \%$ & $1.11[0.73,1.69]$ & & & & \\
\hline Shannon 2010 & 0.131 & 0.3099 & $3.8 \%$ & $1.14[0.62,2.09]$ & & & & \\
\hline Ukoli 2009 & -0.5798 & 0.4721 & $1.8 \%$ & $0.56[0.22,1.41]$ & & & & \\
\hline Ukoli 2010 & 0.3001 & 0.6232 & $1.1 \%$ & $1.35[0.40,4.58]$ & & & & \\
\hline Subtotal $(95 \% \mathrm{Cl})$ & & & $38.6 \%$ & $0.94[0.73,1.19]$ & & & & \\
\hline \multicolumn{9}{|c|}{$\begin{array}{l}\text { Heterogeneity: } \text { Tau }^{2}=0.05 ; \mathrm{Chi}^{2}=14.43, \mathrm{df}=9(\mathrm{P}=0.11) ; \mathrm{I}^{2}=38 \% \\
\text { Test for overall effect: } Z=0.54(\mathrm{P}=0.59)\end{array}$} \\
\hline \multicolumn{9}{|c|}{ 1.1.2 Doco sapentaenoic acid (DPA) } \\
\hline Chavarro 2007 & -0.5108 & 0.2277 & $5.9 \%$ & $0.60[0.38,0.94]$ & & & & \\
\hline Crowe 2008 & -0.0513 & 0.1936 & $7.3 \%$ & $0.95[0.65,1.39]$ & & & & \\
\hline Harvei 1997 & -0.3567 & 0.3745 & $2.8 \%$ & $0.70[0.34,1.46]$ & & & & \\
\hline Park 2009 & -0.2485 & 0.3027 & $3.9 \%$ & $0.78[0.43,1.41]$ & & & & \\
\hline Ukoli 2009 & -0.8214 & 0.4973 & $1.7 \%$ & $0.44[0.17,1.17]$ & & & - & \\
\hline Ukoli 2010 & 0.01 & 0.6059 & $1.2 \%$ & $1.01[0.31,3.31]$ & & & & \\
\hline Subtotal $(95 \% \mathrm{Cl})$ & & & $228 \%$ & $0.76[0.60,0.95]$ & & & & \\
\hline \multicolumn{9}{|c|}{ Heterogeneity: Tau $^{2}=0.00 ; \mathrm{Chi}^{2}=3.89, \mathrm{df}=5(\mathrm{P}=0.57) ; \mathrm{I}^{2}=0 \%$} \\
\hline \multicolumn{9}{|c|}{ Test for overall effect: $Z=2.35(P=0.02)$} \\
\hline \multicolumn{9}{|c|}{ 1.1.3 Eicosapentaenoic acid (EPA) } \\
\hline Crowe 2008 & 0.27 & 0.1618 & $8.9 \%$ & $1.31[0.95,1.80]$ & & & & \\
\hline Godley 1996 & -0.3011 & 0.5918 & $1.2 \%$ & $0.74[0.23,2.36]$ & & & & \\
\hline Havei 1997 & 0.1823 & 0.3199 & $3.6 \%$ & $1.20[0.64,2.25]$ & & & & \\
\hline Mannisto 2003 & 0.1133 & 0.3083 & $3.8 \%$ & $1.12[0.61,2.05]$ & & & & \\
\hline Newcomer 2001 & 0.2624 & 0.4109 & $2.4 \%$ & $1.30[0.58,2.91]$ & & & & \\
\hline Norrish 1999 & -0.5276 & 0.2408 & $5.5 \%$ & $0.59[0.37,0.95]$ & & & & \\
\hline Park 2009 & 0.1044 & 0.211 & $6.6 \%$ & $1.11[0.73,1.68]$ & & & & \\
\hline Shannon 2010 & 0.1133 & 0.2855 & $4.3 \%$ & $1.12[0.64,1.96]$ & & & & \\
\hline Ukoli 2009 & 0.0862 & 0.5102 & $1.6 \%$ & $1.09[0.40,2.96]$ & & & & \\
\hline Ukoli 2010 & -0.1985 & 0.6974 & $0.9 \%$ & $0.82[0.21,3.22]$ & & & & \\
\hline Subtotal $(95 \% \mathrm{Cl})$ & & & $38.7 \%$ & $1.07[0.90,1.28]$ & & & & \\
\hline \multicolumn{9}{|c|}{$\begin{array}{l}\text { Heterogeneity: } \mathrm{Tau}^{2}=0.00 ; \mathrm{Chi}^{2}=8.64, \mathrm{df}=9(\mathrm{P}=0.47) ; \mathrm{I}^{2}=0 \% \\
\text { Test for overall effect: } Z=0.76(P=0.45)\end{array}$} \\
\hline \multirow{3}{*}{\multicolumn{5}{|c|}{$\begin{array}{l}\text { Total }(95 \% \mathrm{Cl}) \\
\text { Heterogeneity: } \text { Tau }^{2}=0.03 ; \mathrm{Chi}^{2}=32.66, \mathrm{df}=25(\mathrm{P}=0.0 .14) ; \mathrm{I}^{\mathbf{2}}=23 \% \\
\text { Test for overall effect: } Z=0.97(\mathrm{P}=0.33) \\
\text { Test for }\end{array}$}} & & & & \\
\hline & & & & & 0.2 & 0.5 & 12 & 5 \\
\hline & & & & & & $=$ High Corum 1 aul & 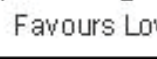 & .ow Serum Level \\
\hline
\end{tabular}

Fig. 2. Forest plot of pooled effect of blood level omega-3 polyunsaturated fatty acid (PUFA) on total prostate cancer risk.

grade prostate tumour. The source of heterogeneity was mainly from the nested case cohort of "The Physician's Health Study." ${ }^{3}$ The authors acknowledged that their subjects were more knowledgeable and provided more reliable information. However, this group may have a generally higher DHA and EPA intake which affected the study's results because of their increased awareness towards healthy practices. The study also failed to present adjustments for confounding variables, such as family history, body mass index and racial ethnicity, which were established risk factors for prostate cancer. When this study was excluded, a significant positive association was noted on fish oil containing long chain $n-3$ PUFA (EPA+DHA) with high grade prostate cancer (Table 4). Factors to consider on this relative association is the healthier lifestyle of patients taking fish oil. These patients tend to be more health conscious, 


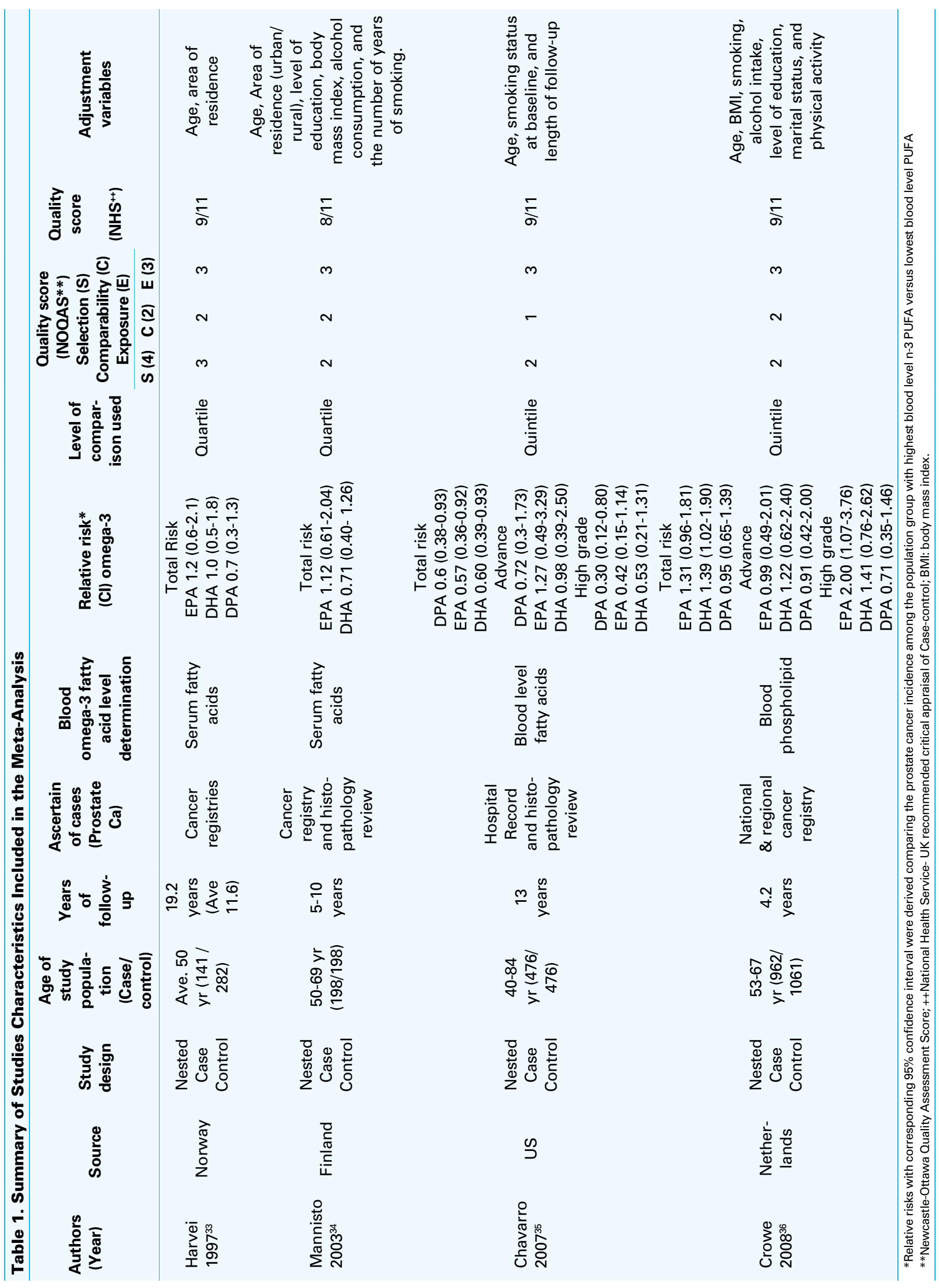




\begin{tabular}{|c|c|c|c|c|c|c|c|}
\hline 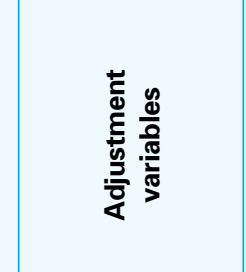 & 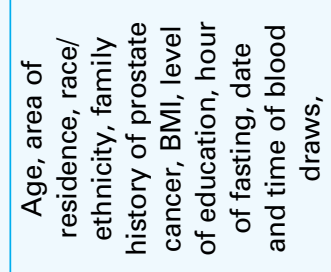 & 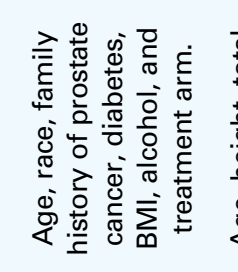 & 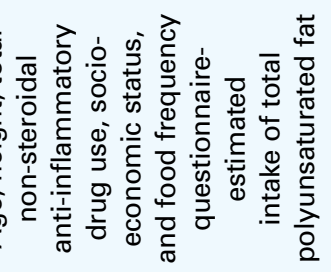 & 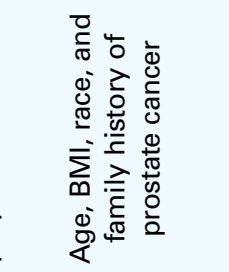 & 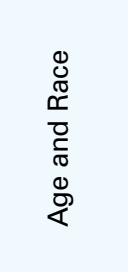 & $\stackrel{8}{8}$ & \\
\hline 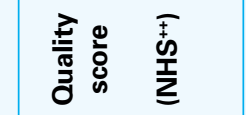 & $\Sigma_{0}^{\Sigma}$ & $\frac{\sigma}{\sigma}$ & $\frac{\Sigma}{\sigma}$ & $\bar{\sigma}$ & $\underset{\infty}{\Gamma}$ & $\underset{\infty}{\bar{\infty}}$ & \\
\hline 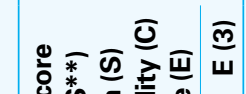 & m & $m$ & m & $m$ & N & $m$ & \\
\hline & N & N & N & $\sim$ & & - & \\
\hline 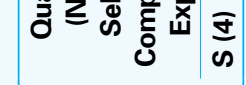 & N & 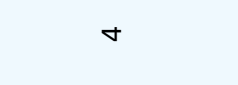 & $m$ & $m$ & $m$ & $m$ & \\
\hline 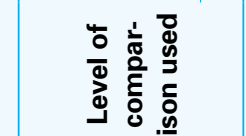 & 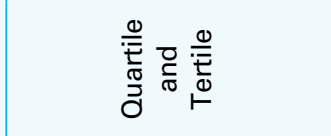 & 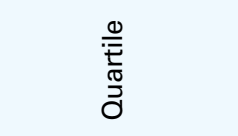 & 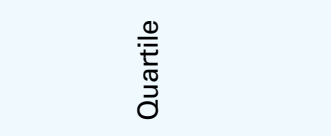 & 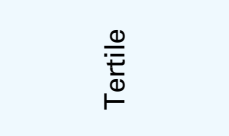 & 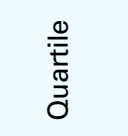 & 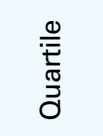 & \\
\hline 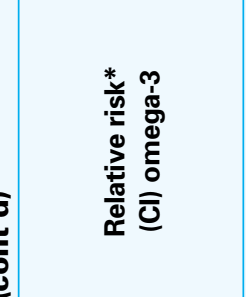 & 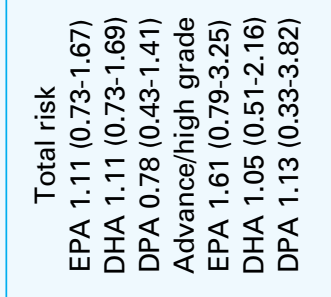 & 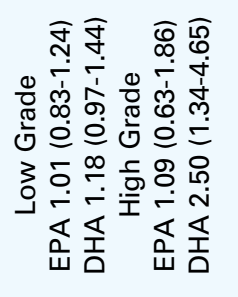 & 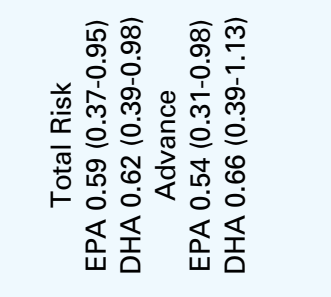 & 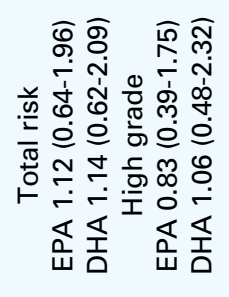 & 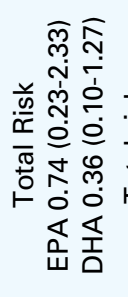 & 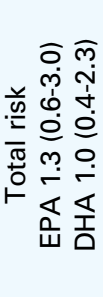 & \\
\hline 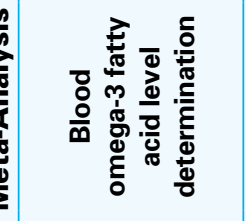 & 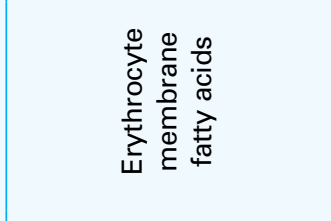 & 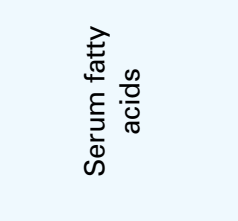 & 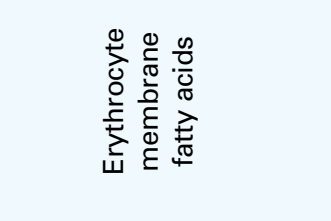 & 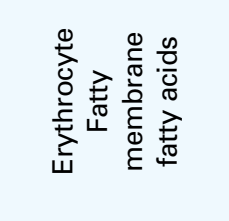 & 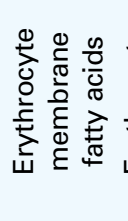 & 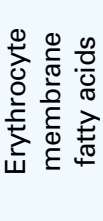 & \\
\hline 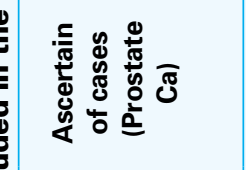 & 辛辛 & 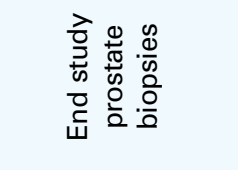 & 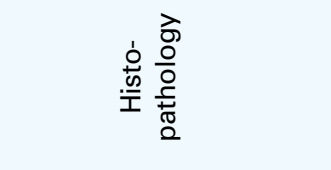 & 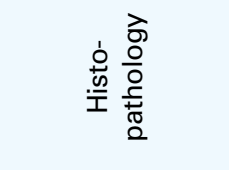 & 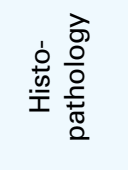 & 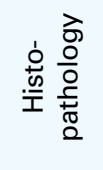 & \\
\hline 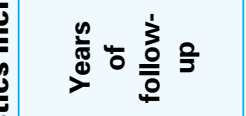 & 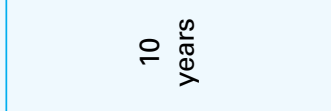 & $\wedge \stackrel{\frac{\infty}{\Phi}}{\stackrel{\varpi}{\supset}}$ & $\stackrel{\pi}{z}$ & 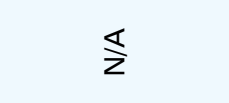 & $\frac{\pi}{z}$ & 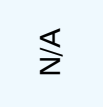 & \\
\hline 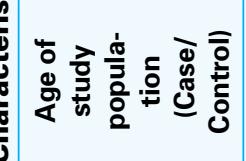 & 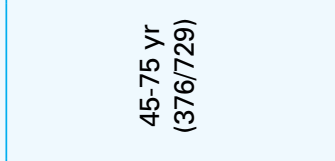 & 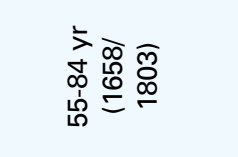 & 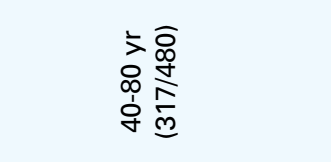 & 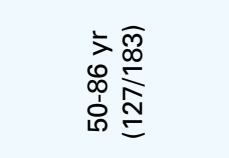 & 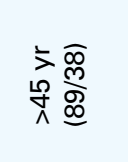 & 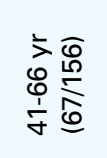 & \\
\hline 窟高 & 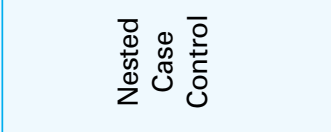 & 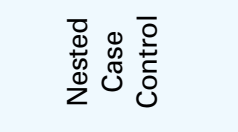 & 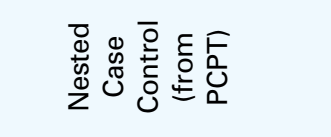 & 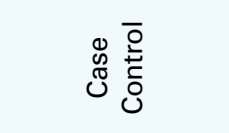 & 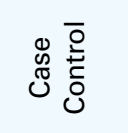 & $\begin{array}{l}\text { 总 } \\
\text { o. } \\
\text { o. }\end{array}$ & \\
\hline ๕̈ & 峁 & 峁 & 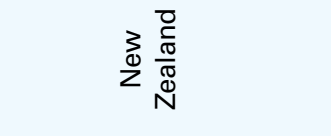 & 心) & 孚 & 离 & \\
\hline 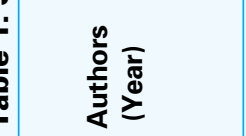 & 高高 & 音愛 & 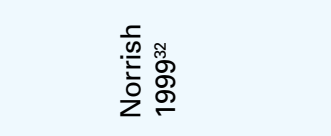 & 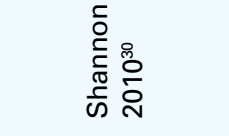 & 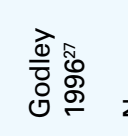 & & \\
\hline
\end{tabular}


which may produce a co-founding factor of early detection via PSA screening due to better health follow-up and health care access. However, the detection of high-grade prostate tumour instead of indolent or total prostate cancer risk among this subgroup is presumed to be due to a biochemical process in the prostate tissue. Since, it is well-illustrated in epidemiological studies that increased prostate cancer incidence due to early detection by vast PSA screening is more significant for general risk or detection of indolent type of prostate cancery. ${ }^{50-52}$

The finding of an association between EPA+DHA with high-grade prostate tumour was quite similar with the findings by the Prostate Cancer Prevention Trial (PCPT). ${ }^{50}$ Nonetheless, there is still debate about whether finasteride induces the development of high-grade prostate tumour or results to a better detection rate by reducing prostate size..$^{50}$ As mentioned earlier, there are inconsistencies regarding the effects of long-chain PUFA, particularly EPA and DHA, in the development of prostate cancer. Some studies have recognized the effects of n-3 PUFA via eicosanoid pathway in cancer prevention, while others have implicated the role of dietary fat in changing the androgen milieu as a causative factor for prostate cancer. The detection of high-grade prostate tumour instead of indolent or total prostate cancer risk was presumed to be due to a biochemical process in the prostate tissue. The since increased early detection of prostate cancer due to PSA screening is more frequent in general risk or indolent type of cancer rather than in the high-grade subtype only. ${ }^{51,52}$

Reports have also shown that marine fish contaminated with environmental toxins, such as polychlorinated biphenyls or methylmercury compounds, can disrupt androgen and estrogen balance and could be linked to high-grade prostate cancer. ${ }^{53-54}$ Furthermore, the presence of long chain n-3 PUFA (DHA and EPA) in the prostate cell's betaoxidative metabolic process leads to the formation of lipid hydroperoxides in the microenvironment of the cell; this can generate reactive species. ${ }^{55-56}$ With chronic exposure to these reactive molecules, the prostate cell can become dysplastic and develop into an aggressive cell.

In this aspect, the possible role of both EPA and DHA needs to be examined further for their use as biomarkers for aggressive disease and to see if a reduction of these n-3 PUFA can decrease the risk. Possible reasons why EPA and DHA, but not DPA, are implicated in aggressive prostate cancer remain to be determined. The association of serum DPA in prostate cancer development still needs to be examined further, since lipid metabolism is far more intricate and genetic variations in individuals may be involved. ${ }^{57}$ 
Chua et al.

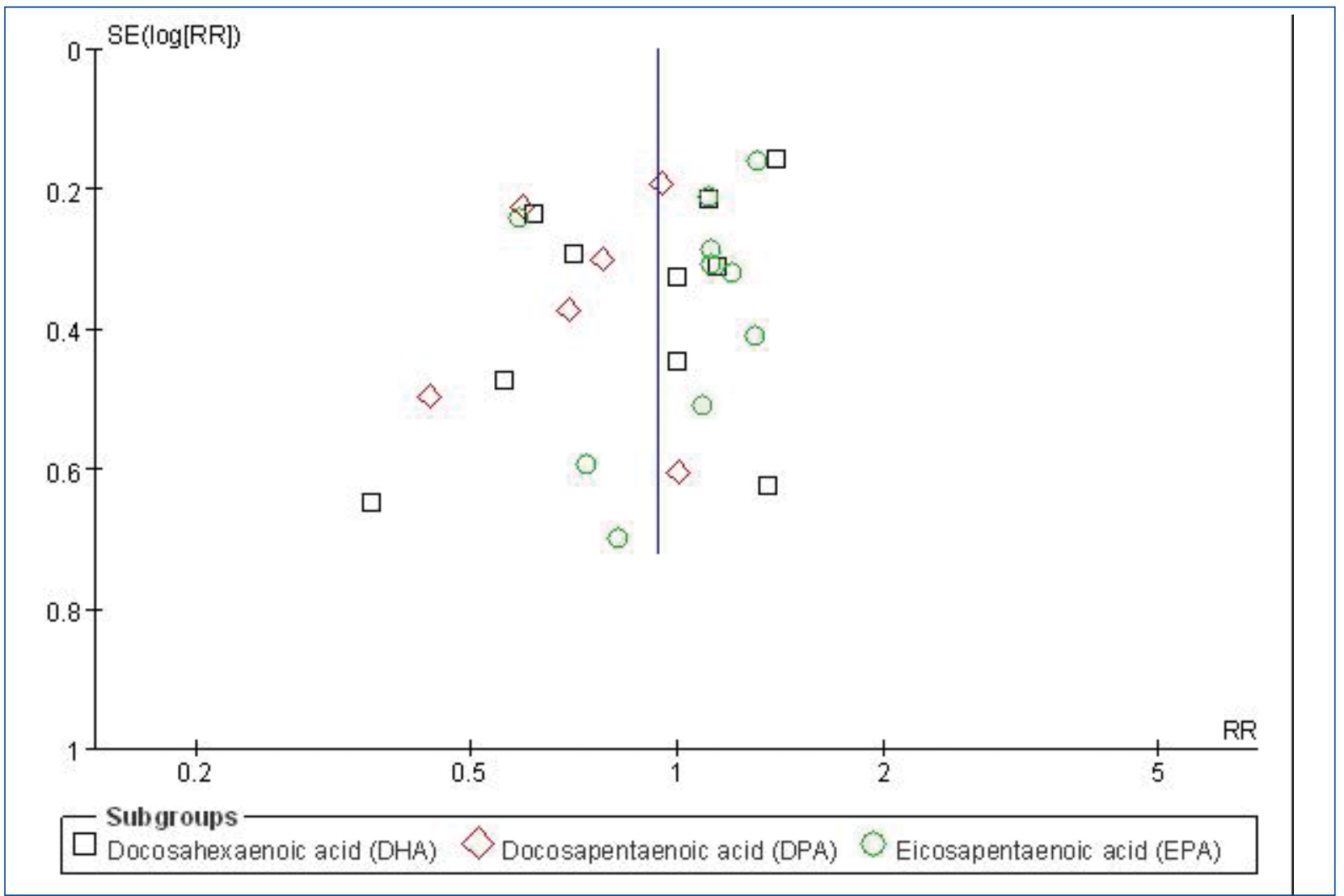

Fig. 3. Publication bias determination using funnel plot.

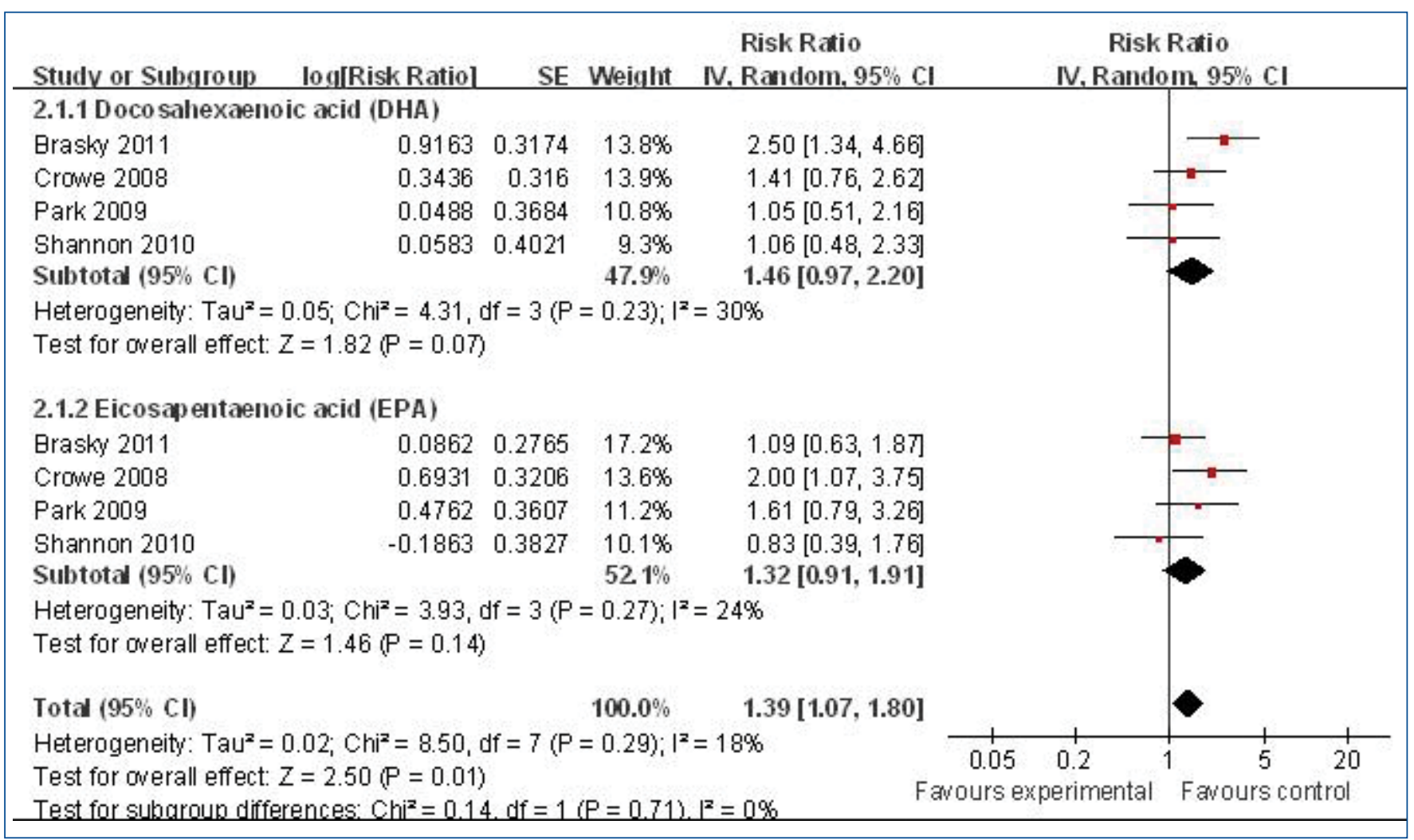

Fig. 4. Forest plot of pooled effect of blood level omega-3 polyunsaturated fatty acid (PUFA) high-grade prostate tumour. 

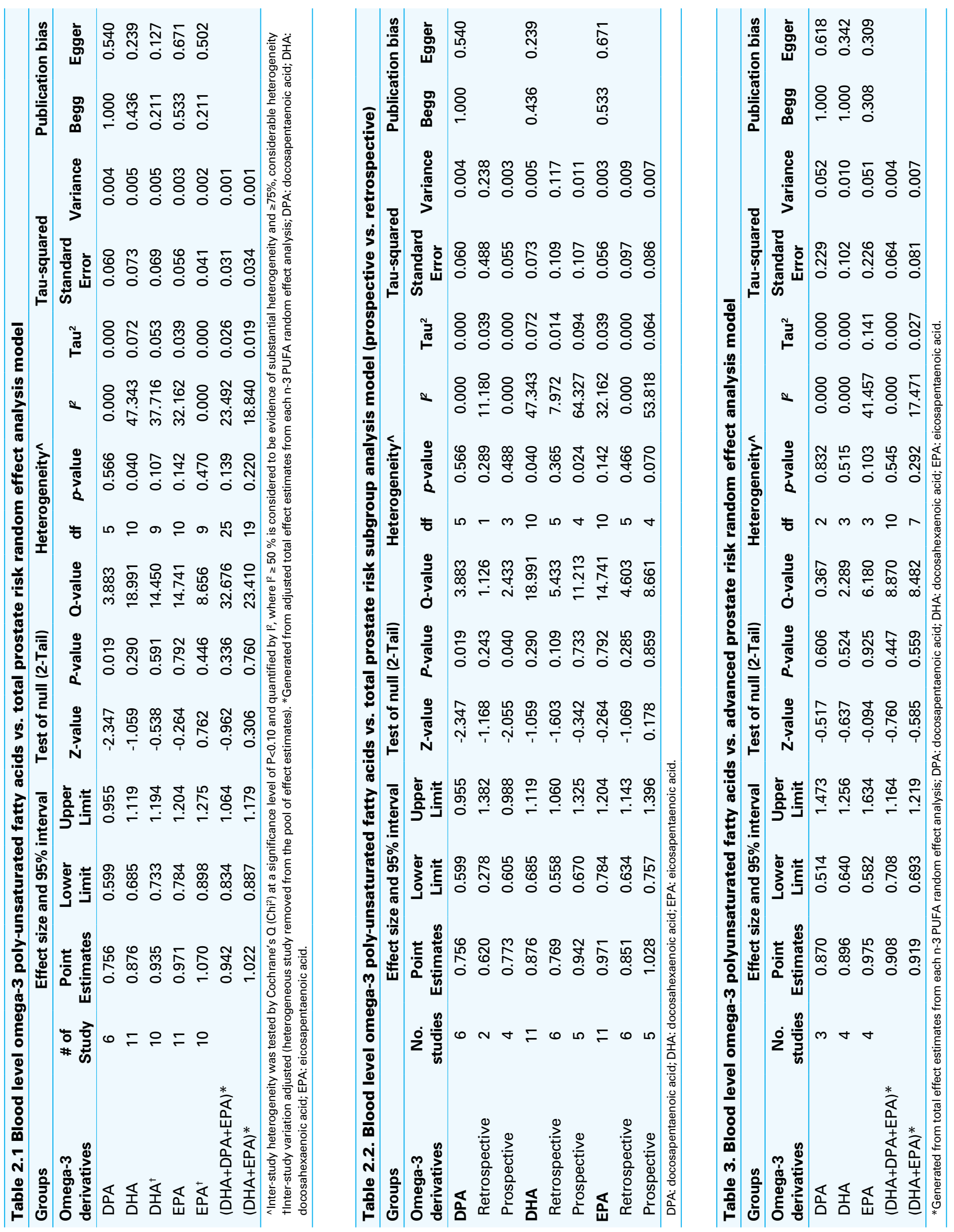


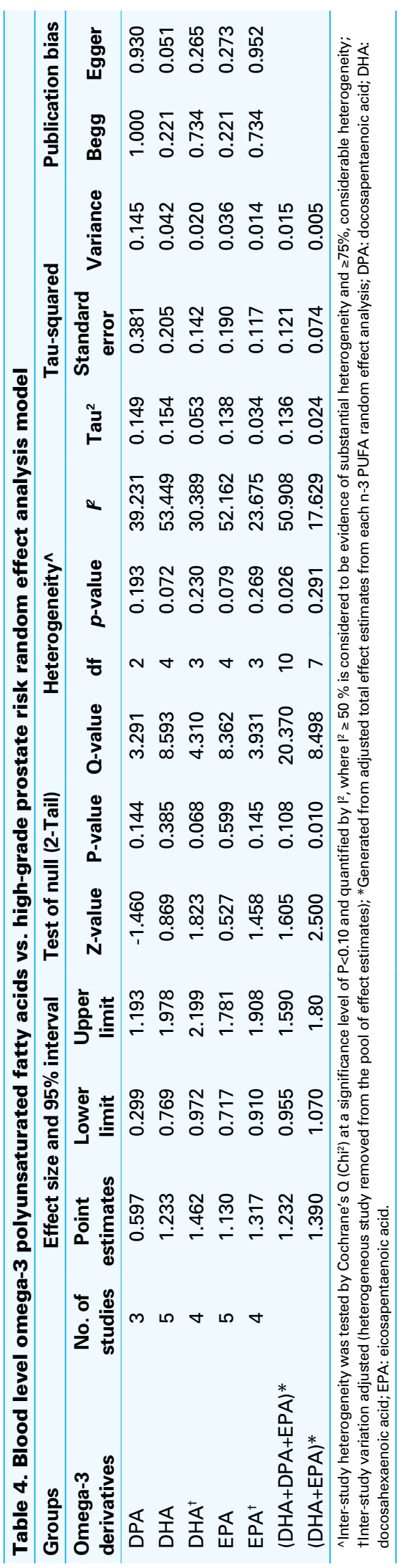

\section{Conclusion}

This meta-analysis provided evidence to show that high blood level n-3 PUFA DPA is associated with reduced risk of prostate cancer. While high blood level of EPA and DHA in combination is associated with increase high-grade prostate tumour risk. These results must be interpreted with caution, since the etiology of prostate cancer is multifactorial and the metabolism of long chain n-3 PUFA in human body is complex.

Competing interests: None declared.

This paper has been peer-reviewed.

\section{References}

1. De Marzo AM, Platz EA, Sutcliffe S, et al. Inflammation in prostate carcinogenesis. Nat Rev Cancer 2007;7:256-69. http://dx.doi.org/10.1038/nrc2090

2. Chan $J M$, Gann PH, Giovannucci EL. Role of diet in prostate cancer development and progression. J Clin Oncol 2005;23:8152-60. http://dx.doi.org/10.1200/JC0.2005.03.1492

3. Chan JM, Stampfer MJ, Ma J, et al. Dairy products, calcium, and prostate cancer risk in the Physicians' Health Study. Am J Clin Nutr 2001;74:549-54.

4. Chan JM, Weinberg V, Magbanua MJ, et al. Nutritional supplements, COX-2 and IGF-1 expression in men on active surveillance for prostate cancer. Cancer Causes Control 201 1;22:141-50. http://dx.doi. $\operatorname{org} / 10.1007 / \mathrm{s} 10552-010-9684-5$

5. Larsson SC, Kumlin M, Ingelman-Sundberg $M$, et al. Dietary long-chain $n-3$ fatty acids for the prevention of cancer: a review of potential mechanisms. Am J Clin Nutr 2004;79:935-45.

6. Carayol M, Grosclaude P, Delpierre C. Prospective studies of dietary alpha-linolenic acid intake and prostate cancer risk: a meta-analysis. Cancer Causes Control 2010;21:347-55. http://dx.doi.org/10.1007/ s10552-009-9465-1

7. Ma RW-L, Chapman K. A systematic review of the effect of diet in prostate cancer prevention and treatment. J Hum Nutr Diet 2009;22:187-99. http://dx.doi.org/10.1111/i.1365-277X.2009.00946.x

8. MacLean CH, Newberry SJ, Mojica WA, et al. Effects of omega-3 fatty acids on cancer risk. JAMA 2006;295:403-15. http://dx.doi.org/10.1001/jama.295.4.403

9. Chua ME, Dy JS. Relationship of Dietary Intake of Omega-3 and Omega-6 Fatty Acids with Risk of Prostate Cancer Development. Philippine Journal of Urology. In Press; 2011.

10. Kohlmeier L. Future of dietary exposure assessment. Am I Clin Nutr 1995;61:S702-9.

11. Byers $T$, Gieseker K. Issues in the design and interpretation of studies of fatty acids and cancer in humans. Am J Clin Nutr 1997;66:S1541-7.

12. Andersen LF, Solvoll K, Drevon CA. Very-long-chain n_3 fatty acids as biomarkers for intake of fish and n_3 fatty acid concentrates. Am J Clin Nutr 1996;64:305-11.

13. Wolk A, Furuheim M, Vessby B. Fatty acid composition of adipose tissue and serum lipids are valid biological markers of dairy fat intake in men. J Nutr 2001;131:828-33.

14. Zock PL, Mensink RP, Harryvan J, et al. Fatty acids in serum cholesteryl esters as quantitative biomarkers of dietary intake in humans. Am J Epidemiol 1997;145:1114-22. http://dx.doi.org/10.1093/ oxfordjournals.aje.0009074

15. Arab L, Akbar J. Biomarkers and the measurement of fatty acids. Public Helath Nutr 2002;5:865-71. http://dx.doi.org/10.1079/PHN2002391

16. Baylin A, Kim MK, Donovan-Palmer A, et al. Fasting whole blood as a biomarker of essential fatty acid intake in epidemiologic studies: comparison with adipose tissue and plasma. Am J Epidemiol 2005;162:373-81. http://dx.doi.org/10.1093/aie/kwi213

17. Moher D, Liberati A, Tetzlaff J, et al. Preferred reporting items nfor systematic reviews and meta-analyses: the PRISMA statement. Ann Intern Med 2009;151:264-9, W64.

18. Letts L, Wilkins S, Law M, et al. Guidelines for Critical Review Form: Qualitative Studies (Version 2.0). 2007. http://www.srs-mcmaster.ca/Portals/20/pdf/ebp/qualguidelines_version2.0.pdf. Accessed April 25, 2013. 
19. Higgins JPT, Green S (editors). Cochrane Handbook for Systematic Reviews of Interventions Version 5.1.0 [updated March 2011]. The Cochrane Collaboration, 2011. Available from www.cochrane-handbook. org. Accessed April 25, 2013.

20. Greenland S. Quantitative methods in review of epidemiologic literature. Epidemiol Rev 1986;9:1-30.

21. Hunter JE, Schmidt FL. Fixed effect vs. random effects meta-analysis models: implications for cumulative research knowledge. Int I Selection Assess 2000;8:275-92. http://dx.doi.org/10.1111/14682389.00156

22. Borenstein M, Hedges L, Higgins J, et al. Comprehensive Meta Analysis Version 2, Biostat, Englewood, NJ; 2005.

23. Review manager (Revman) [Computer program]. Version 5.1. Copenhagen: The Nordic Cochrane Center, Cochrane Collaboration, 2011

24. Egger $M$, Smith $G$, Schneider $M$, et al. Bias in meta-analysis detected by a simple, graphical test. BMJ 1997;315:629-34. http://dx.doi.org/10.1136/bmi.315.7109.629

25. Begg CB, Mazumdar M. Operating characteristics of a rank correlation test for publication bias. Biometrics 1994;50:1088-101. http://dx.doi.org/10.2307/2533446

26. Duval S, Tweedie R. Trim and fill: a simple funnel-plot-based method of testing and adjusting for publication bias in meta-analysis. Biometrics 2000;56:455-63. http://dx.doi.org/10.1111/j.0006341X.2000.00455.x

27. Godley PA, Campbell MK, Gallagher P, et al. Biomarkers of essential fatty acid consumption and risk of prostatic carcinoma. Cancer Epidemiol Biomarkers Prev 1996;5:889-95.

28. Newcomer LM, King IB, Wicklund KG, et al. The association of fatty acids with prostate cancer risk. Prostate 2001;47:262-8. http://dx.doi.org/10.1002/pros.1070

29. Ukoli FA, Akumabor PN, Oguike TC, et al. The association of plasma fatty acids with prostate cancer risk in Nigerians. Ethn Dis 2009;19:454-61.

30. Shannon $A, O^{\prime}$ Malley J, Mori $M$, et al. Erythrocyte fatty acids and prostate cancer risk: A comparison of methods. Prostaglandins Leukot Essent Fatty Acids 2010;83:161-9. http://dx.doi.org/10.1016/i. plefa.2010.06.003

31. Ukoli FA, Fowke JH, Akumabor $P$, et al. The association of plasma fatty acids with prostate cancer risk in African Americans and Africans. J Health Care Poor Underserved 2010;21 (1 Suppl):127-47. http:// dx.doi.org/10.1353/hpu.0.0242

32. Norrish AE, Skeaff CM, Arribas GLB, et al. Prostate cancer risk and consumption of fish oils: A dietary biomarker-based case-control study. Br J Cancer 1999;81:1238-42. http://dx.doi.org/10.1038/ si.bjc.6690835

33. Harvei $S$, Bjerve KS, Tretli $S$, et al. Prediagnostic level of fatty acids in serum phospholipids: omega-3 and omega-6 fatty acids and the risk of prostate cancer. Int J Cancer 1997;71:545-51. http://dx.doi. org/10.1002/(SICI) 1097-0215(19970516)71:4<545::AID-IIC7>3.0.C0;2-U

34. Mannisto S, Pietinen P, Virtanen MJ, et al. Fatty acids and risk of prostate cancer in a nested case-control study in male smokers. Cancer Epidemiol Biomarkers Prev 2003;12:1422-8.

35. Chavarro JE, Stampfer MJ, Li H, et al. A prospective study of polyunsaturated fatty acid levels in blood and prostate cancer risk. Cancer Epidemiol Biomarkers Prev 2007;16:1364-70. http://dx.doi. org/10.1158/1055-9965.EPI-06-1033

36. Crowe FL, Allen NE, Appleby PN, et al. Fatty acid composition of plasma phospholipids and risk of prostate cancer in a case-control analysis nested within the European prospective investigation into cancer and nutrition. Am J Clin Nutr 2008:88:1353-63.

37. Park SY, Wilken LR, Henning SM, et al. Circulating fatty acids and prostate cancer risk in a nested case-control study: the Multiethnic Cohort. Cancer Causes Control 2009;20:211-23. http://dx.doi. org/10.1007/s10552-008-9236-4

38. Brasky TM, Till C, White E, et al. Serum phospholipid fatty acids and prostate cancer risk: results from the prostate cancer prevention trial. Am J Epidemiol 201 1;173:1429-39. http://dx.doi.org/10.1093/ aie/kwr027

39. Meyer BJ, Lane AE, Mann NJ. Comparison of seal oil to tuna oil on plasma lipid levels and blood pressure in hypertriglyceridaemic subjects. Lipids 2009;44:827-35. http://dx.doi.org/10.1007/s1 1745-0093333-3
40. Wang Y, Botolin D, Christian B, et al. Tissue-specific, nutritional, and developmental regulation of rat fatty acid elongases. J Lipid Res 2005;46:706-15. http://dx.doi.org/10.1194/ilr.M400335-JLR200

41. Kaur G, Begg DP, Barr B, et al. Short-term docosapentaenoic acid (22:5n-3) supplementation increases tissue docosapentaenoic acid, DHA and EPA concentrations in rats. Br J Nutr 2009; 103:32-7. http:// dx.doi.org/10.1017/S0007114509991334

42. Holub BJ, Swidinsky P, Park E. Oral Docosapentaenoic Acid (22:5n-3) Is Differentially Incorporated into Phospholipid Pools and Differentially Metabolized to Eicosapentaenoic Acid in Tissues from Young Rats. Lipids 2011;46:399-407. http://dx.doi.org/10.1007/s11745-011-3535-3

43. Henderson RA, Jensen RG, Lammi-Keefe $C \mathrm{~J}$, et al. Effect of fish oil on the fatty acid composition of human milk and maternal and infant erythrocytes. Lipids 1992;27:863-9. http://dx.doi.org/10.1007/ BF02535865

44. Kishida E, Tajiri M, Masuzawa Y. Docosahexaenoic acid enrichment can reduce L929 cell necrosis induced by tumor necrosis factor. Biochim Biophys Acta 2006;1761:454-62. http://dx.doi.org/10.1016/i. bbalip.2006.03.023

45. Careaga MM, Sprecher H. Synthesis of two hydroxy fatty acids from 7,10,13,16,19-docosapentaenoic acid by human platelets. J Biol Chem 1984;259:14413-7.

46. Benistant $C$, Achard $F$, Ben Slama S, et al. Docosapentaenoic acid $(22: 5, n-3)$ : metabolism and effect on prostacyclin production in endothelial cells. Prostag Leukotr Essent Fatty Acids 1996;55:287-92. http:// dx.doi.org/10.1016/S0952-3278(96)90010-1

47. Kelly L, Grehan B, Chiesa AD, et al. The polyunsaturated fatty acids, EPA and DPA exert a protective effect in the hippocampus of the aged rat. Neurobiol Aging 2011;32:2318.e 1-2318.e15. http:// dx.doi/10.1016/ j.neurobiolaging.2010.04.001.

48. Tsuï M, Murota SI, Morita I. Docosapentaenoic acid $(22: 5, n-3)$ suppressed tube-forming activity in endothelial cells induced by vascular endothelial growth factor. Prostag Leukotr Essent Fatty Acids 2003;68:337-42. http://dx.doi.org/10.1016/S0952-3278(03)00025-5

49. Solakivi $\mathrm{T}$, Jaakkola 0 , Kalela A, et al. Lipoprotein docosapentaenoic acid is associated with serum matrix metalloproteinase-9 concentration. Lipids Health Dis 2005;4:8. http://dx.doi.org/10.1186/1476$511 X-4-8$

50. Andriole GL, Humphrey PA, Serfling RJ, et al. High-grade prostate cancer in the Prostate Cancer Prevention Trial: fact or artifact? J Natl Cancer Inst 2007;99:1355-6. http://dx.doi.org/10.1093/inci/diml51

51. Legler JM, Fever EJ, Potosky AL, et al. The role of prostate-specific antigen (PSA) testing patterns in the recent prostate cancer incidence decline in the United States. Cancer Causes Control 1998;9:519-27. http://dx.doi.org/10.1023/A:1008805718310

52. Giovannucci E. Commentary: serum lycopene and prostate cancer progression: a re-consideration of findings from the prostate cancer prevention trial. Cancer Causes Control 2011;22:1055-9. http://dx.doi. org/10.1007/s10552-011-9776-x

53. Brouwer $A$, Longnecker $M P$, Birnbaum $L S$, et al. Characterization of potential endocrine-related health effects at low-dose levels of exposure to PCBS. Environ Health Perspect 1999;107 (Suppl 4):639-49.

54. Ritchie JM, Vial SL, Fuortes $\downarrow$, et al. Comparison of proposed frameworks for grouping polychlorinated biphenyl congener data applied to a case-control pilot study of prostate cancer. Environ Res 2005;98:10413. http://dx.doi.org/10.1016/i.envres.2004.05.013

55. Liu Y. Fatty acid oxidation is a dominant bioenergetic pathway in prostate ancer. Prostate Cancer Prostatic Dis 2006;9:230-4. http://dx.doi.org/10.1038/si.pcan.4500879

56. Federico $\mathrm{A}$, Morgillo $\mathrm{F}$, Tuccillo $\mathrm{C}$, et al. Chronic inflammation and oxidative stress in human carcinogenesis. Int J Cancer 2007;121: 2381-6. http://dx.doi.org/10.1002/iic.23192

57. Lemaitre RN, Tanaka T, Tang W, et al. Genetic Loci Associated with Plasma Phospholipid n-3 Fatty Acids: A Meta-Analysis of Genome-Wide Association Studies from the CHARGE Consortium. PLoS Genet 2011;7:e1002193. http://dx.doi.org/10.1371/journal.pgen.1002193

Correspondence: Dr. Michael Chua, Michael E. Chua, 279 E. Rodriguez Blvd., Cathedral Heights, Quezon City, Philippines; auhc_ekim@yahoo.com 